\title{
SOLVENT EFFECTS ON THE MAGNETIC SHIELDING OF TERTIARY BUTYL ALCOHOL, TERTIARY BUTYL AMINE AND RELATED MOLECULES
}

\author{
Martin Grayson \\ Department of Chemistry, Brook Hill, The University of Sheffield, Sheffield S3 7HF, U.K.
}

(Received September 19, 2004; revised March 26, 2005)

\begin{abstract}
The magnetic shielding and its polarizabilities, have been calculated for tertiary butyl alcohol and tertiary butyl amine. These have been used to rationalise the solvent shifts of the proton spectra of the interesting cosolvent systems with water recently measured by Kipkemboi, et al. Continuum solvation calculations and calculations of Buckingham A and B for relevant nuclei are presented. New parameters relevant to the ${ }^{13} \mathrm{C},{ }^{15} \mathrm{~N}$ and ${ }^{17} \mathrm{O}$ NMR spectra in the same systems have been calculated. There is wider discussion of the validity of chemical shift estimation methods. New calculations on the related molecules $\mathrm{Si}\left(\mathrm{CH}_{3}\right)_{4}$ (TMS), neo-pentane $\mathrm{C}\left(\mathrm{CH}_{3}\right)_{4}$ and tetramethyl ammonium cation $\mathrm{N}\left(\mathrm{CH}_{3}\right)_{4}^{(+)}$have also been presented.
\end{abstract}

KEY WORDS: Solvent effects, Magnetic shielding, Tertiary butyl alcohol, Tertiary butyl amine, Continuum solvation calculations, Chemical shift estimation methods

\section{INTRODUCTION}

Kipkemboi, Kiprono and Easteal have recently published much experimental data of the effect of solvation on the proton magnetic shielding of the tertiary butyl alcohol and amine [1]. This author had previously published calculations on the solvent shifts in TMS, (tetramethylsilane), $\mathrm{Si}\left(\mathrm{CH}_{3}\right)_{4}$, neo-pentane $\mathrm{C}\left(\mathrm{CH}_{3}\right)_{4}$ and tetramethyl ammonium cation $\mathrm{N}\left(\mathrm{CH}_{3}\right)_{4}{ }^{(+)}$[2] and so it was thought timely to present more theoretical data which could be useful in interpreting data from these complex cosolvent systems.

Extensive experimental solvent shift data has already been published for TMS [3, 4]. The molecules modelled previously have perfect $T_{d}$ symmetry. There are 4 equivalent carbons and 12 equivalent protons. In TMS of course these equivalent nuclei are used as references for both protons and ${ }^{13} \mathrm{C}$ in NMR spectroscopy. The previously published experimental work under consideration here used both TMS and DSS, (3-(trimethylsilyl)-1-propane-sulfonic acid), as references, the sulfonic acid being used for some compositions because of its high water solubility whereas TMS is rather insoluble in water.

As computational chemists tend to think of shieldings as absolute rather than relative to a reference molecule so it is worth repeating here the language and equations used in different contexts. The absolute shielding $\sigma$ is defined as:

$$
E=E(1-\infty / 1)
$$

where $\sigma$ is a dimensionless number in ppm, $B$ is the field experienced by the nucleus and $B_{0}$ is the applied magnetic field. $\delta$, the chemical shift is defined as:

$$
\delta=\frac{\nu_{\text {(sample) }}-\nu_{(\text {referenee })}}{\nu_{(\text {operating) }}} \times 10^{6} \text { p.p.m. }
$$

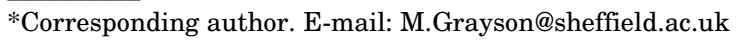


where $v$ is the resonant frequency of the nucleus type in question.

In modern instrumentation the field (B) is fixed and the frequency $(v)$ is effectively swept by electronic control of the pulse shape. The terminology up-field and down-field is thus obsolete. The more the field gets through to the nucleus, i.e. the smaller the absolute shielding, the greater is the energy difference between the nuclear spin states therefore the greater the value of $\delta$ and the higher the resonant frequency. This means that $\delta$ and $v$ versus absolute $\sigma$ move in opposite directions

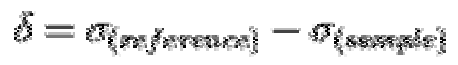

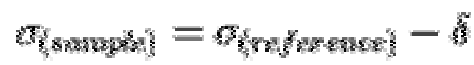

The obsolete but still much used term up-field means more shielded as a larger magnetic field is needed to make the energy difference come into resonance. For the rest of this article $\sigma$ will be used rather than $\delta$ as it is easier to relate to the theoretical literature using the absolute shielding.

Routine experiments must have a reference sample and cannot measure absolute shielding. Absolute shielding measurements have been reviewed by Jameson [5] and Sundholm et al. [6, 7].

For a molecule in solution, fields originating from local electric dipoles change the chemical shift from the gas phase values. The Buckingham, Schaefer and Schneider model, the BSS model [8], from the 1960s has 4 terms:

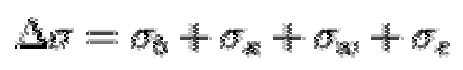

where $\sigma_{\mathrm{b}}$ is the bulk magnetic susceptibility effect, $\sigma_{\mathrm{a}}$ is the effect of the magnetic anisotropy of the solvent and $\sigma_{\mathrm{w}}$ is the van der Waals term largely including dispersion effects. $\sigma_{\mathrm{e}}$ is the electrical reaction field dipole term which we are predominantly considering here. Buckingham [9] expressed these electric field effects by tensors describing the field strength derivatives of the gas phase shielding. Buckingham's original electric field equation was for the shielding of a nucleus in a diatomic:

$$
\sigma=\sigma_{0}-\mathrm{A} F_{\| \text {band }}-\mathrm{B} F^{2}
$$

It can be seen that A, being linear in the field, has a direction, like a dipole moment $\mu$, and this direction must be defined for each problem. The effect of $\mathrm{B}$ is independent of the direction of the field so B is analogous to a polarizability $\alpha$. Similarly B was expected to be always positive, (it usually is).

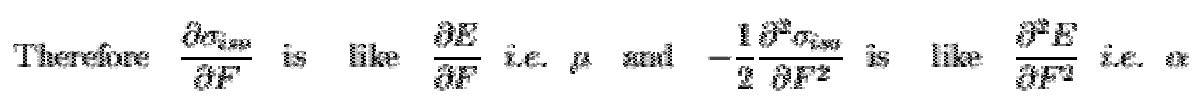

Great care must be taken over the vector direction of A because unlike for $\mu$, electronegativity cannot be used to tell intuitively which direction is correct.

The use of A and B and their spatial definitions have been reviewed by Raynes [10,11] and Grayson [12]. 
Buckingham used a minus sign specifically because the field was expected to reduce the shielding by pulling electrons from strongly shielding $s$-type occupation out into less penetrating $p$ and $d$ orbitals.

Most workers use atomic units (p.p.m. $\mathrm{au}^{-1}$ ) for A and so I have used these rather than the SI units. The conversion factor to the SI unit is

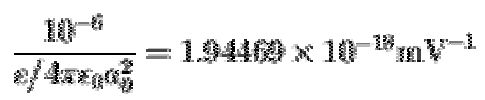

and for $\mathrm{B}$, the second derivative, $\mathrm{ppm} \mathrm{au}^{-2}$ in atomic units, is

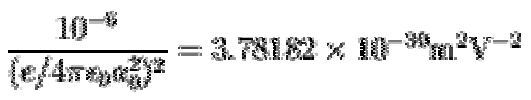

For the molecular dimers of $\mathrm{H}_{2} \mathrm{O}, \mathrm{HF}, \mathrm{NH}_{3}, \mathrm{HCl}$ and $\mathrm{CH}_{3} \mathrm{~F}$ the performance of the Buckingham model is $45 \%$ of the effect on all the protons [13]. When water and HF are removed, leaving the less strongly hydrogen bonded $\mathrm{NH}_{3}, \mathrm{HCl}$ and $\mathrm{CH}_{3} \mathrm{~F}$, the performance of the model is $75 \%$ of the effect for all protons. When only protons in strong field environments are considered the performance is also about $75 \%$ of the reduction in shielding. Therefore a model of the change of the shielding on solvation by a strongly hydrogen bonding solvent such as water using a perturbation by electric fields model without any special hydrogen bond describing parameterisation will not be sufficient but because of the high electric field situation we will get an approximate model of what is happening and a measure of the extra effect caused by strong hydrogen bonding.

\section{COMPUTATIONAL}

The solvation calculations used a spherical cavity model with a radius of the centre of mass to the furthest proton distance plus the van der Waals radius of hydrogen (120 picometres). The cavity sizes used were $339.2 \mathrm{pm}$ for $\mathrm{C}\left(\mathrm{CH}_{3}\right)_{3} \mathrm{NH}_{2}$ and $339.5 \mathrm{pm}$ for $\mathrm{C}\left(\mathrm{CH}_{3}\right)_{3} \mathrm{OH}$. The water dielectric constant (78.5) was used. The multipole expansion up to $L=10$ for the reaction field has been previously found to be adequate, even for non polar, medium sized molecules. The spherical cavity model was thought to be adequate because these molecules are nearly spherical. For ellipsoidal molecules another semi-numerical method such as the PCM method would be more appropriate. (The spherical cavity model allows more of the calculation to be analytical.) The molecular geometries were obtained by optimisation using an SCF wavefunction at the $6-31 G^{* *}[14,15]$ basis level. London Orbitals $[16,17]$ were used for the shieldings and all calculations used the DALTON-1.2.1 [18] program.

Solvation calculations used the Self-Consistent Reaction Field Model [19, 20], as implemented in DALTON. Calculations were repeated at the same geometry using the Sadlej Medium Polarized basis set, (MedPol) [21, 22], which is specifically designed to produce good polarizabilities and therefore hopefully polarizations of other properties, but at a reasonable computational cost.

Experience with the cavity sizes for the current calculation suggested that a slightly smaller cavity than was used in the calculations in reference [2] might be more appropriate and so the previously reported calculations were repeated using equivalent cavity sizes to the current calculation. 
For the calculation of new A values published here a finite field perturbation of \pm 0.002 au is added to the 1-electron Hamiltonian and the SCF calculations repeated for a 2-point finite differencing procedure. Experience has suggested this value is optimum for this sort of calculation. The magnitude of the applied field is a compromise between making a large enough change for accurate derivatives and avoiding contamination from higher order. The optimum field is potentially different for each property depending how much change is induced by the perturbation. As an example where the effect on functional groups in a molecule from electronic or structural changes at a distance is modelled by small changes to a nuclear charge this requires a perturbation to the nuclear charge of \pm 0.002 au [23]. This causes a field of the order of $10^{-3}$ i.e. $\approx \pm 0.002$ au at typical intramolecular distances. Another example is where wavefunctions have no analytical second derivatives of the energy with respect to atomic displacements formulated. Often a finite differencing procedure using atomic position displacements of 0.001 au is used.

\section{RESULTS AND DISCUSSION}

Most experimental NMR obtains chemical shifts with respect to a reference so a calculation with an equivalent basis of the reference molecule must be obtained [24]. Comparing the calculated values of $\sigma_{\mathrm{H}}$ for $-\mathrm{OH}$ in tertiary butanol with the calculated value for TMS at the 6-31G** basis gives a chemical shift of (32.75-32.34) i.e. $+0.4 \mathrm{ppm})$. This is $0.2 \mathrm{ppm}$ different from the experimental gas phase value of $+0.6 \mathrm{ppm}$ [25] but is in reasonable agreement allowing for the expected accuracy of SCF shielding calculations [24]. The chemical shift of the -OH proton is actually coincidentially near zero even though the environment looks very different from the hydrophobic environment of the protons in TMS. The small $0.2 \mathrm{ppm}$ difference could also be due to librational effects in the gas phase as these will be greater for the alcohol than for TMS and would have the effect of increasing the chemical shift slightly. Later data in this paper gives a temperature gradient $d \sigma_{\mathrm{H}}(\mathrm{OH}) / \mathrm{dT}=0.014 / \mathrm{ppmK}^{-1}$ so a $0.2 \mathrm{ppm}$ discrepancy corresponds to a temperature difference of only 7 degrees $\mathrm{K}$.

The ${ }^{13} \mathrm{C}$ values of $\delta$ for $-\mathrm{C}(*) \mathrm{H}_{2} \mathrm{OH}$ calculated here are $+59.0 \mathrm{ppm}$ compared with an experimental value of +50.2 [26]. The discrepancy is probably largely due to the basis set incompleteness of the $6-31 \mathrm{G}^{* *}$ basis. Surprisingly the incompleteness error is greater for the shielding itself, where there is a component of the error connected with the gauge behaviour of the London Orbitals, than it is for the Buckingham parameters. As they are derivatives of $\sigma$ this error is subtracted out.

It is always the case that ${ }^{13} \mathrm{C}$ and particularly ${ }^{15} \mathrm{~N}$ and ${ }^{17} \mathrm{O}$ shieldings are sensitive to the basis being used. The 6-31G** basis and the SCF level of calculation is not large enough to give the definitive shielding but hopefully can give some illuminating insights into the problem. For ${ }^{13} \mathrm{C}$ there are scaling methods [27, 28] where systematic errors have been fitted for moderate calculation levels. These allow for what is on average a $25 \mathrm{ppm}$ discrepancy in the base shielding and a reduction in the experimental range of $\delta$ over a sequence of different carbon environments by 15 percent. As we are principally concerned with differences in $\sigma$ here it was felt that any scaling procedure was not applicable.

The ${ }^{13} \mathrm{C} \delta$ for $-\mathrm{C}\left({ }^{*}\right) \mathrm{H}_{2} \mathrm{NH}_{2}$ is calculated as $+40.8 \mathrm{ppm}$ compared to an experiment of +28.3 [26]. Proton exchange effects in addition to the vibrational effects mentioned earlier would cause the calculation/experiment discrepancy to be smaller, but certainly not by more than $5 \mathrm{ppm}$. The potential $25 \mathrm{ppm}$ basis set scaling error mentioned earlier is a more likely cause of the discrepancy.

The temperature and concentration dependent data of Kipkemboi et al. [1] is examined with reference to data from the new computations. 
The data here in Table 1 shows a continuum solvation calculation, which also has no specific hydrogen bonding is giving $66.7 \%$, comparable to the data in reference [13], of the experimental effect for $t$-butyl-alcohol. However it gives only a small fraction, $6.3 \%$, for the amine. (The amine protons in pure amine are experimentally $4 \mathrm{ppm}$ more shielded than in dilute solution [1]. The continuum solvation model gives only $0.25 \mathrm{ppm}$.) This breakdown of a simple electrostatic model is almost certainly due to protonation of the amine. When the shielding is calculated for a gas phase $\mathrm{C}\left(\mathrm{CH}_{3}\right)_{3} \mathrm{NH}_{3}{ }^{(+)}$at the $6-31 \mathrm{G}^{* *}$ level the shielding of the $-\mathrm{NH}_{3}{ }^{(+)}$ protons is indeed $3.90 \mathrm{ppm}$ lower than the unperturbed amine at $28.44 \mathrm{ppm}$. Though not conclusive this calculation strongly supports the protonated amine hypothesis. Amine inversion is usually too fast for the NMR timescale [29] and so is not likely to be a factor here.

Table 1. Shieldings and solvation energies of the alcohol and amine.

\begin{tabular}{|c|c|c|c|c|c|c|}
\hline & $\begin{array}{l}\sigma_{\mathrm{H}} \\
\mathrm{CH}_{3} \\
\text { protons } \\
(\mathrm{ppm})\end{array}$ & $\begin{array}{l}\sigma_{\mathrm{H}} \\
\text { Heteroatom } \\
\text { proton(s) } \\
(\mathrm{ppm})\end{array}$ & $\begin{array}{l}\sigma_{\mathrm{C}} \\
\mathrm{CH}_{3}(\mathrm{C}) \\
(\mathrm{ppm})\end{array}$ & $\begin{array}{l}\sigma \\
\text { Central } \\
\text { atom } \\
(\mathrm{ppm})\end{array}$ & $\begin{array}{l}\Delta \mathrm{G} \\
\text { solvation } \\
\left(\mathrm{kJ} \mathrm{mole}^{-1}\right)\end{array}$ & $\begin{array}{l}\text { Solvent } \\
\text { cavity } \\
\text { radius } \\
(\mathrm{pm})\end{array}$ \\
\hline $\mathrm{C}\left(\mathrm{CH}_{3}\right)_{3} \mathrm{OH}$ & 31.52 & 32.75 & 173.11 & 175.28 & -7.67 & 339.5 \\
\hline P6-31G** basis & -0.122 & -0.3803 & 0.7070 & 0.2004 & $(\dagger)$ & \\
\hline $\mathrm{C}\left(\mathrm{CH}_{3}\right)_{3} \mathrm{OH}$ & 31.54 & 32.84 & 170.76 & 173.76 & -7.94 & 339.5 \\
\hline Sadlej MedPol & -0.1278 & -0.4008 & 0.5931 & -0.0311 & $(\dagger)$ & \\
\hline $\mathrm{C}\left(\mathrm{CH}_{3}\right)_{3} \mathrm{NH}_{2}$ & 31.36 & 32.34 & 173.01 & 162.53 & -7.40 & 339.2 \\
\hline P6-31G** basis & -0.0123 & -0.1991 & 0.5542 & -0.0679 & $(\dagger)$ & \\
\hline $\mathrm{C}\left(\mathrm{CH}_{3}\right)_{3} \mathrm{NH}_{2}$ & 31.33 & 32.34 & 172.01 & 167.98 & -8.01 & 339.2 \\
\hline Sadlej MedPol & -0.0047 & -0.2546 & 0.1583 & 1.1353 & $(\dagger)$ & \\
\hline
\end{tabular}

$(\dagger)$ - these are $\Delta=\sigma_{\text {solv. }} \sigma_{\text {vac. }}$ from the solvation calculations.

The electric field model was employed in reverse to see what sort of fields gave the required shifts from that term alone. These are shown in Table 2 where the field required at first order only and the field required when second order terms are used is also tabulated. The number in brackets is the field $F$ at $F=\mathrm{A} / \mathrm{B}$ where the contributions from first and second order are equal. The magnitude of field where this happens gives some indication of the effective importance of the experimentally and theoretically difficult $\mathrm{B}$. For the heavier atoms ${ }^{13} \mathrm{C}$ and ${ }^{17} \mathrm{O}$ this can be at the sort of fields experienced in zeolites but for protons the fields where B is important are too large to be considered. Table 3 shows the kind of fields experienced in a collection of representative environments. 0.007 au is what we might expect here.

Table 2. The electric fields required for a given shielding shift.

\begin{tabular}{|l|l|l|l|l|}
\hline & $\begin{array}{l}\text { Change in } \sigma \\
(\mathrm{ppm})\end{array}$ & $\begin{array}{l}\text { 1st order } \\
(\mathrm{au})\end{array}$ & $\begin{array}{l}\text { 2nd order } \\
(\mathrm{au})\end{array}$ & $\begin{array}{l}\mathrm{A} / \mathrm{B} \\
(\mathrm{au})\end{array}$ \\
\hline $\mathrm{C}\left(\mathrm{CH}_{3}\right)_{3} \mathrm{OH}^{*}$ & -0.6 & 0.0067 & 0.0067 & 3.6 \\
\hline $\mathrm{C}^{*}\left(\mathrm{CH}_{3}\right)_{3} \mathrm{NH}_{2}{ }^{*}$ & -4.0 & 0.0500 & 0.0485 & 1.6 \\
\hline $\mathrm{C}^{*} \mathrm{H}_{3}-\mathrm{C}\left(\mathrm{CH}_{3}\right)_{2} \mathrm{OH}$ & +0.7070 & 0.0108 & 0.0093 & 0.0544 \\
\hline $\mathrm{C}^{*} \mathrm{H}_{3}-\mathrm{C}\left(\mathrm{CH}_{3}\right)_{2} \mathrm{NH}_{2}$ & +0.5542 & 0.0042 & 0.0041 & 0.1668 \\
\hline
\end{tabular}

$1 \mathrm{au}=5.14220 \times 10^{11} \mathrm{Vm}^{-1}$. 
Table 3. The electric fields produced in representative chemical environments.

\begin{tabular}{|l|l|l|l|}
\hline & $\mathrm{au}$ & $\mathrm{Vm}^{-1} \times 10^{10}$ & Reference \\
\hline Inside a semiconductor & 0.0002 & 0.010 & {$[40]$} \\
\hline Typical finite field calculation & 0.002 & 0.103 & \\
\hline Protein environment & $0.006->0.008$ & $0.309->0.411$ & {$[41,42]$} \\
\hline Strong zeolite & 0.019 & 1 & {$[43]$} \\
\hline Valence electrons & 0.117 & 6 & {$[43]$} \\
\hline
\end{tabular}

SCF calculations of A were obtained for the protons $\mathrm{CH}_{3} \mathrm{OH}^{(*)}$ and $\mathrm{CH}_{3} \mathrm{NH}_{2}{ }^{(*)}$ using the ccVTZ basis set of Dunning [30,31] in order to examine possible values of A to use. A representative set of proton $A$ values for a series of related molecules is in Table 4. Generic values of $\mathrm{A}=90$ and $\mathrm{B}=25$ were used for $-\mathrm{OH}$ and $\mathrm{A}=80$ and $\mathrm{B}=50$ for $-\mathrm{NH}_{2}$.

Table 4. Representative proton shielding polarizabilities/au in chemical interest order.

\begin{tabular}{|c|c|c|c|c|}
\hline & $A^{\prime \prime}$ & $\mathrm{A}^{\perp}$ & $\mathrm{B}^{\text {iso }}$ & Source \\
\hline $\mathrm{H}_{2}$ & 50.3 & (0) & 93.8 & {$[44]$} \\
\hline $\mathrm{CH}_{4}$ & 76.8 & $(0)$ & 64.2 & (b) [45] \\
\hline $\mathrm{C}_{2} \mathrm{H}_{6}$ & 71.7 & 4.0 & 91.6 & {$[46]$} \\
\hline Generic $(\mathrm{C}-\mathrm{H})$ & 72 & & & {$[46,47]$} \\
\hline$\left(\mathrm{CH}_{3}{ }^{(*)}\right)_{3} \mathrm{COH}$ & 66.6 & & $\approx 50$ & $(\dagger)$ \\
\hline$\left(\mathrm{CH}_{3}{ }^{(*)}\right)_{3} \mathrm{CNH}_{2}$ & 64.3 & & $\approx 93$ & $(\dagger)$ \\
\hline $\mathrm{CH}_{3} \mathrm{~F}$ & 62.0 & 5.6 & 65.0 & [46] \\
\hline $\mathrm{CH}_{3} \mathrm{Cl}$ & 67.8 & 17.7 & 80.0 & [48] \\
\hline $\mathrm{CH}_{3} \mathrm{Br}$ & 87.6 & 33.8 & 120.8 & [12] \\
\hline $\mathrm{CH}_{3} \mathrm{I}$ & 95.7 & 37.3 & 150.0 & [12] \\
\hline $\mathrm{H}_{2} \mathrm{O}$ & 91.0 & -10.7 & 19.8 & [49] \\
\hline$\left(\mathrm{CH}_{3}\right)_{3} \mathrm{COH}^{(*)}$ & 81.9 & & $\approx 0$ & $(\dagger)$ \\
\hline $\mathrm{CH}_{3} \mathrm{OH}^{(*)}$ & 91.8 & 26.8 & & [12] \\
\hline $\mathrm{CH}_{3} \mathrm{OH}^{(*)}$ & 88.1 & & $\approx-900$ & $(\dagger)$ \\
\hline$\left(\mathrm{CH}_{3}\right)_{3} \mathrm{CNH}_{2}{ }^{\left({ }^{*}\right)}$ & $\approx 67.3$ & & $\approx 140$ & $(\dagger)$ \\
\hline $\mathrm{CH}_{3} \mathrm{NH}_{2}{ }^{(*)}$ & 83.4 & & $\approx-500$ & $(\dagger)$ \\
\hline $\mathrm{NH}_{3}$ & 89.8 & -8.0 & 56.7 & [49] \\
\hline $\mathrm{CH}_{3} \mathrm{Li}$ & 97.9 & 25.8 & 115.2 & [12] \\
\hline $\mathrm{CH}_{3} \mathrm{Na}$ & 97.0 & 24.1 & 1487.5 & [12] \\
\hline $\mathrm{CH}_{3} \mathrm{~K}$ & 115.2 & 75.6 & 1800.0 & [12] \\
\hline $\mathrm{C}\left(\mathrm{CH}_{3}\right)_{4}$ & 77.6 & (0) & 75.0 & {$[2]$} \\
\hline $\mathrm{Si}\left(\mathrm{CH}_{3}\right)_{4}$ & 88.7 & (0) & 94.2 & [2] \\
\hline $\mathrm{N}\left(\mathrm{CH}_{3}\right)_{4}{ }^{+}$ & 69.7 & (0) & 33.3 & {$[2]$} \\
\hline
\end{tabular}

$(\dagger)$ - this work. $(0)$ zero by symmetry. The approximate values of $\mathrm{B},(\approx)$, have the perpendicular component of the tensor set equal to the parallel component. The values for $\left(\mathrm{CH}^{(*)}{ }_{3}\right)_{3} \mathrm{COH}$ and $\left(\mathrm{CH}^{(*)}{ }_{3}\right)_{3} \mathrm{CNH}_{2}$ are for the representative proton with the $\mathrm{C}_{\mathrm{s}}$ site symmetry.

It can be seen that $\mathrm{A}$ for a $\mathrm{X}-\mathrm{H}$ bond varies little: $50 \mathrm{ppm}$ for the special case of $\mathrm{H}_{2}$, many values in the 80-90 range, which is reduced to 62 where electronegative substituents are attached and increases to over 100 for very electropositive substituents.

Table 5 is an illustrative set of ${ }^{13} \mathrm{C}$ A values where the attached groups have different electronegativities. This table also contains the new numbers for the ${ }^{13} \mathrm{C}$ shieldings of $\mathrm{C}^{*} \mathrm{H}_{3}-\mathrm{C}\left(\mathrm{CH}_{3}\right)_{2} \mathrm{OH}$ and $\mathrm{C}^{*} \mathrm{H}_{3}-\mathrm{C}\left(\mathrm{CH}_{3}\right)_{2} \mathrm{NH}_{2}$. (It should be noted that as the $\mathrm{A}$ values of these 
molecules are negative and the charge on the $\mathrm{C}$-atoms is $\delta$ - the shielding increases in a solvated environment.)

Table 5. Some carbon shielding polarizabilities in value order.

\begin{tabular}{|c|c|c|c|}
\hline & $\begin{array}{l}\mathrm{A} \\
\left(\mathrm{ppm} \mathrm{au^{-1 }}\right)\end{array}$ & $\begin{array}{l}\mathrm{B}_{\text {iso }} \\
\left(\mathrm{ppm} \mathrm{au}{ }^{-2}\right)\end{array}$ & Source \\
\hline $\mathrm{CH}_{3} \mathrm{Na}$ & -712.1 & 37575.0 & [12] \\
\hline $\mathrm{CH}_{3} \mathrm{~K}$ & -344.7 & 34716.7 & [12] \\
\hline $\mathrm{CH}_{3} \mathrm{Li}$ & -233.4 & 11358.3 & [12] \\
\hline $\mathrm{C}^{*} \mathrm{H}_{3}-\mathrm{C}\left(\mathrm{CH}_{3}\right)_{2} \mathrm{NH}_{2}$ & -133.4 & $8 \times 10^{2}$ & $(\dagger)$ \\
\hline $\mathrm{C}\left(\mathrm{C}^{*} \mathrm{H}_{3}\right)_{4}$ & -125.0 & 737.5 & {$[2]$} \\
\hline $\mathrm{Si}\left(\mathrm{C}^{*} \mathrm{H}_{3}\right)_{4}$ & -67.2 & 558.3 & [2] \\
\hline $\mathrm{C}^{*} \mathrm{H}_{3}-\mathrm{C}\left(\mathrm{CH}_{3}\right)_{2} \mathrm{OH}$ & -65.3 & $12 \times 10^{2}$ & $(\dagger)$ \\
\hline $\mathrm{C}_{2}^{*}{ }_{2} \mathrm{H}_{6}$ & -49.2 & 1361.8 & {$[50]$} \\
\hline $\mathrm{N}\left(\mathrm{C}^{*} \mathrm{H}_{3}\right)_{4}(+)$ & 33.7 & 754.2 & [2] \\
\hline$\left.\left(\mathrm{CH}_{3}\right)_{3} \mathrm{C}\right)^{(*)} \mathrm{NH}_{2}$ & 50.4 & $18 \times 10^{2}$ & $(\dagger)$ \\
\hline $\mathrm{CH}_{3} \mathrm{NH}_{2}$ & 98.9 & & [12] \\
\hline$\left(\mathrm{CH}_{3}\right)_{3} \mathrm{C}^{(*)} \mathrm{OH}$ & 134.8 & $15 \times 10^{2}$ & $(\dagger)$ \\
\hline $\mathrm{CH}_{3} \mathrm{OH}$ & 150.2 & & [12] \\
\hline $\mathrm{C}^{*} \mathrm{H}_{3} \mathrm{Cl}$ & 219.1 & 1290.2 & {$[50]$} \\
\hline $\mathrm{C}^{*} \mathrm{H}_{3} \mathrm{~F}$ & 222.0 & 853.4 & [50] \\
\hline $\mathrm{C}^{*}\left(\mathrm{CH}_{3}\right)_{4}$ & $(0)$ & 1650.0 & [2] \\
\hline $\mathrm{C}^{*} \mathrm{H}_{4}$ & $(0)$ & 134.8 & [50] \\
\hline
\end{tabular}

$(\dagger)$ - this work. B values quoted to only 2 figures are lacking some of the components due to the low site symmetry [51].

The shifts of the order of half a ppm, (the calculated solvation changes of +0.7070 and +0.5542 ), could be induced by the fields inside a protein environment whereas the amine proton shift of 4 ppm cannot possibly be ascribed to electric field effects, giving more evidence for the protonation hypothesis, (see Tables 2 and 3 ).

The ${ }^{13} \mathrm{C}$ shielding parameter A (Table 5) goes negative for carbons attached to electron donating groups vis $\mathrm{CH}_{3} \mathrm{Na}$ etc. whereas parameter $\mathrm{A}$ becomes positive for carbons attached to electron withdrawing groups as in the $\mathrm{CH}_{3}$-halogen examples. $\mathrm{CH}_{3}-\mathrm{C}\left(\mathrm{CH}_{3}\right)_{2} \mathrm{OH}$ and $\mathrm{CH}_{3}-\mathrm{C}\left(\mathrm{CH}_{3}\right)_{2} \mathrm{NH}_{2}$ happily fall into the expected electronegativity sequence.

$\mathrm{A}^{\perp}$ is quoted for completeness and is zero for many environments. See the review articles [10-12] for a full discussion.

In reference [1] figure 1 showing the water proton shielding in a water/butanol mixture, as $100 \% \mathrm{H}_{2} \mathrm{O}$ goes to pure butanol $\sigma$ slightly decreases by $0.1 \mathrm{ppm}$ at about $10 \%$ butanol then increases by $0.6 \mathrm{ppm}$ as $100 \%$ butanol is approached. What we are seeing here is the hydrophobic hydration as discussed in reference [1], which is largest at lower temperature. The above is the behaviour at $263 \mathrm{~K}$. As the temperature increases the blip disappears and the range increases until at $313 \mathrm{~K}$ there is no blip and an increase of $0.8 \mathrm{ppm}$. These features cannot be modelled by continuum solvation models alone as they are created by a hydrogen bonded water structure.

Reference [1] figure 2 deals with the butanol $-\mathrm{OH}$ proton with the above composition variation. Here the shielding increases in general monotonically as hydrogen bonding is disrupted. At temperatures of $300 \mathrm{~K}$ and below as pure alcohol is approached the shielding begins to decrease as alcohol-alcohol hydrogen bonds are being formed. Above $300 \mathrm{~K}$ the butanol -OH proton shielding increases monotonically by $0.6 \mathrm{ppm}$ as the higher temperatures are capable of disrupting the formation of the weaker alcohol-alcohol hydrogen bonds. As has been

Bull. Chem. Soc. Ethiop. 2005, 19(2) 
described in reference [13] proton shielding invariably decreases in a hydrogen bonding situation.

In figure 3 of reference [1] we have the proton in $\mathrm{H}_{2} \mathrm{O}$ in the water amine mixture $\sigma_{\mathrm{H}}$ monotonically increasing with a very slight blip as for the alcohol at temperatures below $298 \mathrm{~K}$. The increase here is larger at $4 \mathrm{ppm}$ suggesting that the amine group is more hydrogen bond disrupting, i.e. more hydrophobic than an - $\mathrm{OH}$ group or that something very different from - $\mathrm{OH}$ is happening. This could be protonation. The $\mathrm{p} K_{\mathrm{a}}$ of the $t$-butyl amine's conjugate acid is 10.68 so the amine will be protonated in aqueous solution. Exchange is taking place rapidly so only one proton signal is seen.

Figure 4 of reference [1] shows the temperature dependence of the proton resonance in the alcohol water mixture, where the authors have worked out gradient $d \sigma_{\mathrm{H}}(\mathrm{OH}) / \mathrm{dT}$ equal to +0.014 ppm K $\mathrm{K}^{-1}$

Figure 5 of reference [1] shows the temperature dependence of the proton resonance in the amine water mixture is more composition dependent than for the alcohol, (conforming with the idea that amines are more hydrophobic than alcohols).

Several temperature and composition derivatives are shown in Table 10. All these derivatives are positive because the phenomena all disrupt hydrogen bonding therefore making the $\sigma_{\mathrm{H}}$ of more like that of gas phase water i.e. more shielded.

The previously published data on TMS using the earlier cavity size [2] is qualitatively in agreement with the experimental data [3,4] but the calculation gave too small a shift. It was then thought that the shift was too small because of deficiencies in the basis set but it is now suspected that the problem was too large a cavity size causing insufficient generation of a realistic continuum field. (It is of course often possible to match experiment by changing the cavity size, not a very satisfactory procedure, so a systematic procedure for choosing sizes and shapes of cavity must be adopted.) Those calculations have been repeated with a new cavity size and the larger Sadlej MedPol basis set for comparison. The new calculations give a change which is $60 \%$ of the $0.1 \mathrm{ppm}$ changes reported in reference [3]. Given that we have neglected some terms in the BSS model this might actually be reasonable agreement.

It is appropriate here to give a little technical warning about how to use continuum solvation calculation energies. The solvation energy from Dalton is not the solvation interaction quoted in the output of a single continuum solvation run. That energy uses the perturbed wavefunction not the unperturbed gas phase wavefunction. The unperturbed wavefunction will always have a slightly more negative energy than the perturbed one as it is variationally optimised for the gas phase. Therefore the real solvation energy is slightly smaller than the one quoted in the program output.

To put the shieldings and solvation energies, (Table 1), of our alcohol and amine in context Table 6 shows the equivalent data for 3 related molecules containing the tertiary-butyl group. In addition Table 7 is an illustrative selection of solvation energies for familiar chemical species. Singly charged ions on average interact with the solvent to the extent of about $2 / 3$ of a chemical bond, divalent ions about 2.5 chemical bonds, and the small trivalent ions are producing solvation energies equivalent to about 5 chemical bonds. The molecules considered here including TMS are only solvated to about $8 \mathrm{~kJ}$ per mole and $\mathrm{N}\left(\mathrm{CH}_{3}\right)_{4}{ }^{(+)}$is well shielded by its methyl groups and is only solvated by about half a chemical bond. As expected the aqueous solvation of the hydrocarbon $\mathrm{C}\left(\mathrm{CH}_{3}\right)_{4}$ is not energetically favoured.

It is noted that the experimental $\mathrm{CH}_{4} \Delta G_{\text {solv }}$ is positive at $+8.37 \mathrm{~kJ}$ per mole. This is showing the hydrophobic effect whereas a methane molecule will interact with a continuum dielectric depending on the cavity model being used to the extent of $-1 \mathrm{~kJ}$ per mole, as it has a finite quadrupole moment: $6.17 \times 10^{-50} \mathrm{Cm}^{3}$ [32]. These weak multipole and dispersion interactions are however strong enough for methane/water to form clathrates, the hydrate which locks up a large percentage of the world's methane. Methane-hydrate (clathrate) has an organised 
structure [33, 34], where the interaction is energetically favourable but potentially unstable. These gas hydrates could be a large and important resource for energy needs. Their physical chemistry involves hydrophobicity, hydration, and van der Waals forces but is beyond the scope of this paper.

Table 6. Shieldings and solvation energies of the $T_{d}$ molecules.

\begin{tabular}{|c|c|c|c|c|c|}
\hline & $\begin{array}{l}\sigma_{\mathrm{H}} \\
\mathrm{CH}_{3} \\
\text { protons } \\
(\mathrm{ppm})\end{array}$ & $\begin{array}{l}\sigma_{\mathrm{C}} \\
\mathrm{CH}_{3} \\
(\mathrm{ppm})\end{array}$ & $\begin{array}{l}\sigma \\
\text { (Central } \\
\text { Atom }) \\
(\mathrm{ppm})\end{array}$ & $\begin{array}{l}\Delta \mathrm{G} \\
\text { solvation } \\
(\mathrm{kJ} \text { per mole })\end{array}$ & $\begin{array}{l}\text { Solvent } \\
\text { cavity } \\
\text { radius } \\
(\mathrm{pm})\end{array}$ \\
\hline $\mathrm{N}\left(\mathrm{CH}_{3}\right)_{4}{ }^{(+)}$ & 29.40 & 154.06 & 244.21 & -164.93 & 416.5 \\
\hline Ref [2] & -0.0001 & 0.0013 & 0.0233 & $(\dagger)$ & \\
\hline This work & 29.40 & 154.06 & 244.21 & -210.13 & 330.9 \\
\hline P6-31G basis & -0.0136 & 0.1611 & 0.2569 & $(\dagger)$ & \\
\hline This work & 29.46 & 149.18 & 228.50 & -210.26 & 330.9 \\
\hline Sadlej MedPol & -0.0151 & -0.1872 & 0.3240 & $(\dagger)$ & \\
\hline $\mathrm{C}\left(\mathrm{CH}_{3}\right)_{4}$ & 31.44 & 174.39 & 179.88 & -0.16 & 425.5 \\
\hline $\operatorname{Ref}[2]$ & -0.0014 & 0.0697 & -0.0254 & $(\dagger)$ & \\
\hline This work & 31.44 & 174.39 & 179.88 & -1.39 & 337.7 \\
\hline P6-31G ${ }^{\text {basis }}$ & -0.0131 & 0.5517 & -0.1075 & $(\dagger)$ & \\
\hline This work & 31.52 & 173.00 & 171.08 & -1.66 & 337.7 \\
\hline Sadlej MedPol & -0.0035 & 0.4023 & -0.0315 & $(\dagger)$ & \\
\hline $\mathrm{Si}\left(\mathrm{CH}_{3}\right)_{4}$ & 32.34 & 203.30 & 448.65 & -0.83 & 443.5 \\
\hline Ref [2] & -0.0014 & 0.1292 & 0.0490 & $(\dagger)$ & \\
\hline This work & 32.34 & 203.30 & 448.65 & -9.20 & 351.0 \\
\hline P6-31G basis & -0.0580 & 2.5118 & 0.3824 & $(\dagger)$ & \\
\hline This work & 32.51 & 202.84 & 404.48 & n.a. & 351.0 \\
\hline$(*)$ & & & & & \\
\hline
\end{tabular}

$(\dagger)$ - these are $\Delta=\sigma_{\text {solv. }}-\sigma_{\text {vac. }}$ from the solvation calculations. $(*)$ the continuum solvation calculation with the Sadlej basis could not be converged.

Table 7. A selection of solvation energies.

\begin{tabular}{|c|c|c|c|c|c|}
\hline & $\Delta \mathrm{G}\left(\mathrm{kJ} \mathrm{mole}^{-1}\right)$ & Source & & $\Delta \mathrm{G}\left(\mathrm{kJ} \mathrm{mole}^{-1}\right)$ & Source \\
\hline Methane & +8.37 & {$[52]$} & $\mathrm{Na}^{+}$ & -405 & {$[53]$} \\
\hline $\mathrm{C}\left(\mathrm{CH}_{3}\right)_{4}$ & $(\dagger)-1.66$ & This work & $\mathrm{F}$ & -506 & [53] \\
\hline $\mathrm{Si}\left(\mathrm{CH}_{3}\right)_{4}$ & $(\dagger)-9.20$ & This work & $\mathrm{C}^{-}$ & -364 & [53] \\
\hline Adenine & -10 & {$[54]$} & $\mathrm{Br}^{-}$ & -337 & [53] \\
\hline Cytosine & -15 & [54] & $\mathrm{I}^{-}$ & -300 & [55] \\
\hline Guanine & -13 & [54] & $\mathrm{OH}^{-}$ & -444 & {$[56]$} \\
\hline Thymine & -2.3 & [54] & $\mathrm{NO}_{3}{ }^{-}$ & -272 & [56] \\
\hline $\mathrm{C}\left(\mathrm{CH}_{3}\right)_{3} \mathrm{OH}$ & $(\dagger)-7.94$ & This work & $\mathrm{N}_{3^{-}}$ & -310 & [56] \\
\hline $\mathrm{C}\left(\mathrm{CH}_{3}\right)_{3} \mathrm{NH}_{2}$ & $(\dagger)-8.01$ & This work & $\mathrm{Ca}^{2+}$ & -1580 & [53] \\
\hline $\mathrm{NH}_{4}^{+}$ & -331 & {$[56]$} & $\mathrm{Zn}^{2+}$ & -2040 & [55] \\
\hline $\mathrm{N}\left(\mathrm{CH}_{3}\right)_{4}{ }^{+}$ & (†) -210.26 & This work & $\mathrm{SO}_{4}^{2-}$ & $(\dagger)-927.98$ & [35] \\
\hline $\mathrm{H}_{3} \mathrm{O}^{+}$ & -435 & {$[56]$} & $\mathrm{CO}_{3}{ }^{2-}$ & $(\dagger)-1022.25$ & [35] \\
\hline $\mathrm{H}^{+}$ & -1090 & [55] & $\mathrm{Al}^{3+}$ & -4680 & [55] \\
\hline $\mathrm{Li}^{+}$ & -520 & [53] & $\mathrm{La}^{3+}$ & -3300 & [55] \\
\hline
\end{tabular}

$(\dagger)$ - a calculated rather than an experimental value. 
There is a general rule $[35,36]$ that the shielding shifts seem to go in shells. The outer atoms get their charge enhanced by solvation and the shielding changes accordingly. The next inner shell of atoms has a change of shielding in the opposite direction so we have the effect of alternate shells of shielding and deshielding. This is currently speculation from an insufficient collection of partially published results but Raza and Raynes [37] discussed this several years ago and give some experimental evidence in the ${ }^{13} \mathrm{C} \mathrm{NMR} \mathrm{spectra} \mathrm{of} \mathrm{Si}\left(\mathrm{OCH}_{3}\right)_{4}$.

The Buckingham parameters for the heteroatoms in $\mathrm{C}\left(\mathrm{CH}_{3}\right)_{3} \mathrm{NH}_{2}$ and $\mathrm{C}\left(\mathrm{CH}_{3}\right)_{3} \mathrm{OH}$ have also been calculated (Table 8 ). ${ }^{17} \mathrm{O}$ NMR is very sensitive to the chemical environment. For instance ozone has the two inequivalent oxygen sites separated by 566 ppm [38]. In general ${ }^{17} \mathrm{O}$ A values are larger than their ${ }^{13} \mathrm{C}$ equivalents. The charge on both ${ }^{17} \mathrm{O}$ and ${ }^{15} \mathrm{~N}$ nuclei in these molecules is $\delta$ - and as expected the shielding increases (Table 9). The A parameter has its largest value for the direction perpendicular to the $\mathrm{C}-\mathrm{X}$ bond for both molecules. This is because the field in this direction interferes more with the lone pairs and causes a magnitude reduction in the negative paramagnetic contribution which has the effect of increasing the shielding. The direction of the field which increases the shielding is the one which pulls the lone-pair electrons towards the nucleus. (A field in the other direction would of course increase the intensity of the lone-pair magnetic dipole transition and decrease the shielding.)

Table 8. New heteroatom shielding polarizabilities.

\begin{tabular}{|l|l|l|l|}
\hline & $\begin{array}{l}\mathrm{A}^{\mathrm{C}-\mathrm{X}} \\
\left(\mathrm{ppm} \mathrm{au}^{-1}\right)\end{array}$ & $\begin{array}{l}\mathrm{A} \perp \\
\left(\mathrm{ppm} \mathrm{au}{ }^{-1}\right)\end{array}$ & $\begin{array}{l}\mathrm{B}^{\text {iso }} \\
\left(\mathrm{ppm} \mathrm{au}^{-2}\right)\end{array}$ \\
\hline $\mathrm{C}\left(\mathrm{CH}_{3}\right)_{3} \mathrm{O}^{*} \mathrm{H}$ & 447.1 & 4767 \\
\hline $\mathrm{P} 6-31 \mathrm{G}^{* *}$ & 38.7 & 436.1 & 3429 \\
\hline Sadlej MedPol & 163.9 & 223.9 & 1217 \\
\hline $\mathrm{C}\left(\mathrm{CH}_{3}\right)_{3} \mathrm{~N}_{2} \mathrm{H}_{2}$ & 198.6 & 2250 \\
\hline P6-31G** & 136.4 & 149.7 & \multicolumn{3}{|l|}{} \\
\hline Sadlej MedPol &
\end{tabular}

Table 9. Shieldings and shifts of carbons attached to heteroatoms and the heteroatoms themselves.

\begin{tabular}{|l|l|l|l|l|}
\hline & $\begin{array}{l}\sigma_{\mathrm{C}} \\
(\mathrm{ppm})\end{array}$ & $\begin{array}{l}\Delta \sigma_{\mathrm{C}} \\
(\mathrm{ppm})\end{array}$ & $\begin{array}{l}\sigma_{\mathrm{X}} \\
(\mathrm{ppm})\end{array}$ & $\begin{array}{l}\Delta \sigma_{\mathrm{X}} \\
(\mathrm{ppm})\end{array}$ \\
\hline $\mathrm{C}\left(\mathrm{CH}_{3}\right)_{3} \mathrm{OH} \mathrm{P6-31G**}$ & 144.25 & -0.1894 & 289.89 & 3.5703 \\
\hline Sadlej MedPol & 136.21 & -0.2897 & 269.91 & 2.9400 \\
\hline $\mathrm{C}\left(\mathrm{CH}_{3}\right)_{3} \mathrm{NH}_{2} \mathrm{P6}-31 \mathrm{G}^{* *}$ & 162.53 & -0.0679 & 225.22 & 2.5219 \\
\hline Sadlej MedPol & 155.22 & 0.0147 & 216.94 & 2.3524 \\
\hline
\end{tabular}

$(\dagger)$ - these are $\Delta=\sigma_{\text {solv. }}-\sigma_{\text {vac. }}$ from the solvation calculations.

The ${ }^{17} \mathrm{O}$ and ${ }^{15} \mathrm{~N}$ A values are both negative. This is analogous to the situation for ${ }^{13} \mathrm{C}$ attached to atoms or groups which are more electropositive. (All aliphatic carbon functional groups are more electropositive than nitrogen and oxygen.)

In the ${ }^{15} \mathrm{~N}$ NMR of amines protonation causes an increase in the shielding of the ${ }^{15} \mathrm{~N}$ nucleus due to the loss of the strong paramagnetic influence of the lone pair [39]. However ${ }^{15} \mathrm{~N}$ NMR is 5 orders of magnitude weaker than proton NMR so it is not such a useful technique. These large values of $\mathrm{A}$ in the lone pair direction mean that the field at which a change of about $3 \mathrm{ppm}$ can occur are within the fields inside proteins range. 
Table 10. Derivative sieldings of protons and the ${ }^{17} \mathrm{O}$ nucleus of water.

Composition derivatives

\begin{tabular}{|c|c|}
\hline $\begin{array}{l}\frac{\partial \sigma_{H}}{\partial \%(-\mathrm{OH})} \\
(\mathrm{ppm})\end{array}$ & 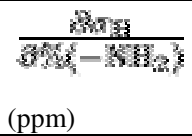 \\
\hline+0.08 & +0.04 \\
\hline Ref. [1] & Ref. [1] \\
\hline
\end{tabular}

Temperature derivatives

\begin{tabular}{|c|c|c|c|}
\hline 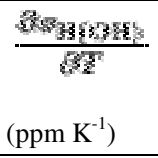 & 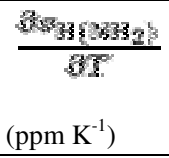 & 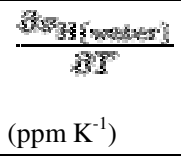 & $\begin{array}{l}\frac{\partial \sigma_{\mathrm{O}}(\text { water })}{\partial T} \\
\left(\mathrm{ppm} \mathrm{K}^{-1}\right)\end{array}$ \\
\hline+0.014 & +0.015 & +0.014 & +0.05 \\
\hline Ref. [1] & Ref. [1] & Ref. [1] & Ref. [57] \\
\hline
\end{tabular}

\section{CONCLUSIONS}

NMR data from the solvation of tertiary butyl alcohol and tertiary butyl amine has been used to illuminate a general discussion of magnetic shielding models and solvation. The model parameters give reasonable agreement with experiment on both sign and magnitude of changes. Also the signs and magnitudes of the NMR parameters are shown to be rational in a scheme of field strengths and the electronegativity of substituents. Extension of the methodologies to other molecules in weakly interacting situations looks promising.

\section{ACKNOWLEDGEMENTS}

The author would like to thank all the developers of the DALTON program for making this work possible. I wish to acknowledge the use of the Yorkshire Universities' White Rose Grid computing service.

\section{REFERENCES}

1. Kipkemboi, P.K.; Kiprono, P.C.; Easteal, A.J. Bull. Chem. Soc. Ethiop. 2002, 16, 187.

2. Grayson, M.; Chittenden, P. Int. J. Mol. Sci. 2000, 1, 49.

3. Bacon, M.; Maciel, G.E. J. Am. Chem. Soc. 1973, 95, 2413.

4. Bacon, M.; Maciel, G.E.; Musker, W.K.; Scholl, R. J. Am. Chem. Soc. 1971, 93, 2537.

5. Jameson, C.J. in The Encyclopedia of Nuclear Magnetic Resonance, Vol. 2, Grant, D.M.; Harris, R.K. (Eds.); Wiley: Chichester; 1996; p 1273.

6. Sundholm, D.; Gauss, J.; Schäfer, A. J. Chem. Phys. 1996, 105, 11051.

7. Sundholm, D.; Gauss, J. Mol. Phys. 1997, 92, 1007.

8. Buckingham, A.D.; Schaefer, T.; Schneider, W.G. J. Chem. Phys. 1960, 32, 1227.

9. Buckingham, A.D. Can. J. Chem. 1960, 38, 300. 
10. Raynes, W.T. in Nuclear Magnetic Shieldings and Molecular Structure, Tossell, J.A. (Ed.); Proceedings of the NATO Advanced Research Workshop on the Calculation of NMR Shielding constants and their use in the Determination of the Geometric and Electronic Structures of Molecules and Solids, Kluwer Academic Publishers: Maryland; 1993; pp 401420.

11. Raynes, W.T. in The Encyclopedia of Nuclear Magnetic Resonance, Vol. 3, Grant, D.M.; Harris, R.K. (Eds.); Wiley: Chichester; 1996; p1846.

12. Grayson, M. The Computation and Experimental Derivation of NMR Shielding Polarizabilities, in Recent Research Developments in Quantum Chemistry, Vol. 6, Transworld Research Network: Trivandrum, India; 2002; p 469.

13. Grayson, M.; Dagger, G. Hydrogen Bonding and Nuclear Magnetic Shielding, Some Calculations and Interpretations, in Recent Research Developments in Molecular Physics, Vol. 2, Transworld Research Network: Trivandrum, India; 2004, p 9.

14. Hehre W.J.; Ditchford R.; Pople J.A. J. Chem. Phys. 1972, 56, 2257.

15. Foresman, J.B.; Frisch, A. Exploring Chemistry with Electronic Structure Methods, 2nd ed., Gaussian: Pittsburgh, U.S.A.; 1993.

16. Pulay, P.; Hinton, J.F. in The Encyclopedia of Nuclear Magnetic Resonance, Vol. 7, Grant, D.M.; Harris, R.K. (Eds.); Wiley: Chichester; 1996; p 4334.

17. Ruud, K.; Helgaker, T.; Kobayashi, R.; Jørgensen, P.; Bak, K.L.; Jensen, H.J.Aa. J. Chem. Phys. 1994, 100, 8178.

18. Dalton, A molecular electronic structure program, Release 1.2 2001, written by Helgaker, T.; Jensen, H.J.Aa.; Jørgensen, P.; Olsen, J.; Ruud, K.; Ågren, H.; Auer, A.A.; Bak, K.L.; Bakken, V.; Christiansen, O.; Coriani, S.; Dahle, P.; Dalskov, E.K.; Enevoldsen, T.; Fernandez, B.; Hättig, C.; Hald, K.; Halkier, A.; Heiberg, H.; Hettema, H.; Jonsson, D.; Kirpekar, S.; Kobayashi, R.; Koch, H.; Mikkelsen, K.V.; Norman, P.; Packer, M.J.; Pedersen, T.B.; Ruden, T.A.; Sanchez, A.; Saue, T.; Sauer, S.P.A.; Schimmelpfennig, B.; Sylvester-Hvid, K.O.; Taylor, P.R.; Vahtras, O. http://www.kjemi.uio.no/software/dalton/dalton.html.

19. Mikkelsen, K.V.; Dalgaard, E.; Swanstrøm, P. J. Phys. Chem. 1987, 91, 3081.

20. Mikkelsen, K.V.; Ågren, H.; Jensen, H.J.Aa.; Helgaker, T. J. Chem. Phys. 1988, 89, 3086.

21. Sadlej, A.J. Collection Czech. Chem. Commun. 1988, 53, 1995.

22. Sadlej, A.J. Theor. Chim. Acta. 1991, 79, 123.

23. Grayson, M. Int. J. Quantum Chem., 1997, 61, 919.

24. Cramer, C.J. Essentials of Computational Chemistry, 2nd ed., John Wiley: Chichester; 2004; pp 344-348.

25. True, N.S. in The Encyclopedia of Spectroscopy and Spectrometry, Vol. 1, Lindon, J.C.; Tranter, G.E.; Holmes, J.L. (Eds.); Academic Press: London; 2000; p 660.

26. Farrant, R.D.; Lindon, J.C.; in Encyclopedia of Spectroscopy and Spectrometry, Lindon, J.C.; Tranter, G.E.; Holmes, J.L. (Eds.); Academic Press: London; 2000; p 159.

27. Sebag, A.B.; Forsyth, D.A.; Plante, M.A.; J. Org. Chem. 2001, $20,91$.

28. Giesen, D.J.; Zumbulyadis, N. Phys. Chem. Chem. Phys. 2002, 4, 5498.

29. Siddall, T.H.; in Encyclopedia of Nuclear Magnetic Resonance, Vol. 5,Grant, D.M.; Harris, R.K. (Ed.); Wiley: Chichester; 1996; p2922.

30. Dunning, T.H. Jr. J. Chem. Phys. 1989, 90, 1007.

31. Woon, D.E.; Dunning, T.H. Jr. J. Chem. Phys. 1995, 103, 4572.

32. Birnbaum, G.; Buechele, A.; Jiang, T.; Joslin, C.G.; Goldman, S. Molec. Phys. 1998, 93, 573.

33. Sloan, E.D. Clathrate Hydrates of Natural Gases, Marcel Dekker: New York; 1998.

34. [http://www.pet.hw.ac.uk/research/hydrate/index.html] accessed 13th August 2004. 
35. Grayson, M. J. Mol. Struct. 2001, 602-603, 429.

36. Cammi, R.; Mennucci, B.; Tomasi, J. J. Chem. Phys. 1999, 110, 7627.

37. Raza, M.A.; Raynes, W.T. Mol. Phys. 1970, 19, 199.

38. Solomon, I.J.; Keith, J.N.; Kacmarek, A.J.; Raney, J.K.. J. Am. Chem. Soc. 1968, 90, 5408.

39. Roberts, J.D.; in The Encyclopedia of Nuclear Magnetic Resonance, Vol. 5, Grant, D.M.; Harris, R.K. (Ed.); Wiley: Chichester; 1996; p 3386.

40. Pachioni, G.; Lomas, J.R.; Illas, F. J. Mol. Catalysis 1997, 119, 263.

41. Horsley, W.J.; Sternlicht, H. J. Am.. Chem. Soc. 1968, 90, 3738.

42. Augspurger, J.; Pearson, J.G.; Oldfield, E.; Dykstra, C.E.; Deok Park, K.; Schwartz, D. J. Magn. Reson. 1992, 100, 342.

43. Náray-Szabó, G. in Recent Research Developments in Physical Chemistry, Vol. 6, Transworld Research Network: Trivandrum, India; 2002, p 567.

44. Augspurger, J.D.; Dykstra, C.E. J. phys. Chem. 1991, 95, 9230.

45. Cybulski, S.M.; Bishop, D.M. Molec. Phys. 1998, 93, 739.

46. Grayson, M.; Raynes, W.T. Magn. Reson. Chem. 1995, 33, 138.

47. Zürcher, R.F. Progr. NMR Spectrosc. 1967, 2, 205.

48. Grayson, M.; Raynes, W.T. Molec. Phys. 1994, 81, 533.

49. Grayson, M.; Raynes, W.T. 1994, 218, 270.

50. Grayson, M.; Raynes, W.T. Mol. Phys. 1994, 81, 533.

51. Raynes, W.T.; Ratcliffe, R. Mol. Phys. 1979, 37, 571.

52. Chambers, C.C.; Hawkins, G.D.; Cramer, C.J.; Truhlar, D.G. J. Phys.. Chem. 1996, 100, 16385.

53. Atkins, P.W. Physical Chemistry, 3rd ed., Oxford University Press: Oxford; 1986.

54. Li, J.; Cramer, C.J.; Truhlar, D.G. Biophys. Chem. 1999, 78, 147.

55. Barrow, G.M. Physical Chemistry, 4th ed., McGraw-Hill; New York; 1979.

56. Liotard, D.A.; Hawkins, G.D.; Lynch, G.C.; Cramer, C.J.; Truhlar, D.G. J. Comput. Chem. $1995,16,422$.

57. Gerothanassis, I.P. in The Encyclopedia of Nuclear Magnetic Resonance, Vol. 5, Grant, D.M.; Harris, R.K. (Eds.); Wiley: Chichester; 1996; p 3430. 